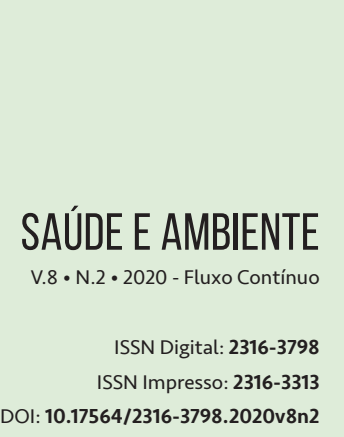

DOI: $10.17564 / 2316-3798.2020 v 8 n 2$

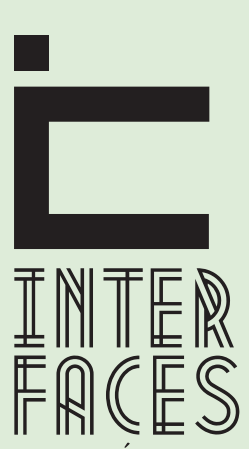

CIENTÍFICAS

\section{CORPO VIVIDO DE ALUNOS COM DEFICIÊNCIA: OLHAR DE GESTORES E DE FUNCIONÁRIOS DE UMA ESCOLA PÚBLICA}

LIVING BODY OF STUDENTS WITH DISABILITIES: LOOK AT MANAGERS AND EMPLOYEES OF A PUBLIC SCHOOL

CUERPO VIVO DE ESTUDIANTES COM DISCAPACIDADES: EL PUNTO DE VISTA DE LOS GERENTES Y EMPLEADOS DE UMA ESCUELA PÚBLICA
Betânia Nicácio Brasiliano ${ }^{1}$ Laís Barbosa Alves ${ }^{2}$ Soraya Dayanna Guimarães Santos ${ }^{3}$

\section{RESUMO}

A corporeidade pode ser entendida como a forma com que percebemos nossos corpos por meio da representação em nossa mente. Desta maneira, investigar como o corpo das pessoas com deficiência é percebido possibilitará um maior entendimento de como as relações com os corpos desses sujeitos são estabelecidas. 0 objetivo do presente estudo foi analisar o olhar de gestores e de funcionários de uma escola pública sobre o corpo de alunos com deficiência. Realizou-se entrevista semiestruturada com dois gestores e três funcionários de uma escola estadual da Zona da Mata Mineira. Para análise dos dados, utilizou-se a análise de conteúdo de Bardin. Tivemos como principais resultados que o olhar de gestores e de funcionários da escola é cercado pelo discurso da "normalidade" e da "superproteção", além do ambiente escolar não estar preparado para incluir os alunos que possuem deficiência. Desta maneira, existe a necessidade de desconstruir essa forma estigmatizada e cercada de preconceitos acerca do corpo da pessoa com deficiência, devendo-se valorizar o potencial humano e suas relações estabelecidas a partir dele.

\section{PALAVRAS-CHAVE}

Deficiência. Alunos. Gestores e funcionários. 


\section{ABSTRACT}

Corporeality can be understood as the way which we perceive our bodies through representation in our mind. In this way, investigating how the body of people with disabilities is perceived will enable a greater understanding of how relationships with the bodies of the individuals are established. The aim of this study was to analyze the views of managers and employees of a public school on the body of students with disabilities. A semi-structured interview was conducted with two managers and three employees of the state school in Zona da Mata Mineira. For data analysis, Bardin's content analysis was used. We had as main results that the view of school managers and employees is surrounded by the discourse of "normality" and "overprotection", in addition to the school environment not being prepared to include students with disabilities. Thus, there is a need to deconstruct this stigmatized form and surrounded by prejudices about the body of the person with disabilities, and the human potential and its relationships established through it should be valued.

\section{KEYWORDS}

Disability, students, managers and employees

\section{RESUMEN}

La corporalidad puede entenderse como la forma en que percibimos nuestros cuerpos a través de la representación en nuestra mente. De esta manera, investigar cómo se percibe el cuerpo de las personas con discapacidad permitirá una mejor comprensión de cómo se establecen las relaciones con los cuerpos de estas personas. El objetivo de este estudio fue analizar las opiniones de gerentes y empleados de una escuela pública sobre el cuerpo de estudiantes con discapacidades. Se realizó una entrevista semiestructurada con dos gerentes y tres empleados de una escuela estatal en la Zona da Mata Mineira. Para el análisis de datos, se utilizó el análisis de contenido de Bardin. Tuvimos como principales resultados, que la opinión de los gerentes y empleados de la escuela está rodeada por el discurso de "normalidad” y “sobreprotección”, además de que el entorno escolar no está preparado para incluir a estudiantes con discapacidades. Por lo tanto, es necesaria la deconstrucción de esa forma estigmatizada y rodeada de prejuicios sobre el cuerpo de la persona con discapacidad, y se debe valorar el potencial humano y sus relaciones establecidas a través de él. 


\section{PALABRAS CLAVE}

discapacidad, estudiantes, gerentes y empleados

\section{INTRODUCÇÃO}

O corpo pode ser entendido como um local que permite encontros vinculados ao ambiente em que habita e entre o sujeito que ali se encontra, o qual carrega consigo objetos que fazem parte de seu significado. 0 corpo vivido compreende um fenômeno biológico e subjetivo, cuja sua finalidade é estar presente no mundo e nele interagir (LIMA et al., 2015).

Por sua vez, a forma com que percebemos nossos corpos e os compreendemos, a partir da representação em nossa mente, pode ser entendida como corporeidade, sendo este um conceito que traz em voga 0 movimento, o gesto, a expressividade e a presença (MERLEAU-PONTY, 1999 apud LIMA et al., 2015).

Conforme o avançar dos tempos, diferentes percepções sobre os corpos vão sendo construídas, de acordo com a interação entre o corpo vivido e a sociedade, e suas necessidades acerca desta (GUGEL, 2007).

O olhar da sociedade sobre o corpo do indivíduo com deficiência também sofreu mudanças ao longo do tempo. 0 nascimento de pessoas com deficiência era encarado como castigo de Deus, e estas eram consideradas seres diabólicos que deveriam ser castigados para que fossem purificados. Por outro lado, no Egito, as pessoas com deficiência se integravam em todas as classes sociais hierarquizadas, como os faraós, nobres, altos funcionários, artesãos, agricultores e escravos (GUGEL, 2007).

Para os gregos, que valorizavam a boa condição física e estética do corpo, as pessoas com deficiência deveriam ser abandonadas/mortas. Com o surgimento do cristianismo, iniciou-se a ideia de caridade, auxílio aos pobres, aos doentes e às pessoas com deficiência. Apesar de haver um distanciamento social neste período, estes não eram mais sacrificados, mesmo que ainda fossem discriminados.

Após a Segunda Guerra Mundial, iniciou-se uma maior preocupação com os direitos das pessoas com deficiência, assim como, no Brasil. Uma das conquistas desse fato foi a criação de documentos legais, a partir da década de 1990, assegurando o direito das pessoas com deficiência ao ensino regular. A exemplo, tem-se:

Declaração de Salamanca (1994), que trata dos princípios, política e prática em Educação Especial, com o objetivo de fornecer diretrizes para formulações e reformas políticas, assim como, educacionais, em relação às pessoas com deficiência;

A Lei de Diretrizes e Bases da Educação (LDBEN nº 9394/96) que, em seu capítulo V, define a Educação Especial como modalidade escolar oferecida no ensino regular para os educandos com deficiência, garantindo o apoio de serviços especializados para atender as necessidades dessa população;

A Lei Brasileira de Inclusão da pessoa com deficiência, n⿳0 13.146/2015 (LBI- Estatuto da Pessoa com Deficiência), destinada a assegurar e promover o exercício dos direitos e das liberdades fundamentais por pessoa com deficiência, visando sua inclusão social e cidadania. 
A inclusão de crianças e adolescentes no ensino regular implica na necessidade de tornar a escola um espaço onde as pessoas com deficiência possam conhecer seu corpo e sua corporeidade, refletir e vivenciar as práticas pedagógicas de forma integral, para que possam se tornar adultos críticos, criativos e ativos perante as necessidades de se viver em sociedade (LIMA et al., 2015).

A Base Nacional Comum Curricular propõe formas de organização interdisciplinar dos componentes curriculares e de fortalecer a competência pedagógica das equipes escolares, de forma a promover a adoção de estratégias mais dinâmicas, interativas e colaborativas de gerir o ensino e a aprendizagem. Igualmente, requer o compromisso com os alunos com deficiência, reconhecendo a necessidade de práticas pedagógicas inclusivas e de diferenciação curricular, conforme estabelecido na LBI (BRASIL, 2018).

Desta forma, o gestor educacional tem uma árdua tarefa de buscar o equilíbrio entre os aspectos pedagógicos e administrativos, com a percepção de que o primeiro se constitui como essencial e deve privilegiar a qualidade, por interferir diretamente no resultado da formação dos estudantes, enquanto o segundo deve dar condições necessárias para o desenvolvimento pedagógico (SILVA, 2009).

Durante o processo de inclusão escolar, torna-se necessário o engajamento de todos os membros da equipe educacional, sejam eles docentes, diretores ou funcionários, para que juntos e com seus papéis específicos, planejem ações e programas direcionados à inclusão, possibilitando sua efetivação neste ambiente (SANT’ANA, 2005).

Neste sentido, o estudo de De Souza e colaboradores (2018) descreve um trabalho com vistas à inclusão escolar que contou com a colaboração de 160 servidores do Instituto Federal do Sul de Minas Gerais, utilizando a educação Finlandesa como referência para construir um plano de ação para Educação Inclusiva. Foi desenvolvido um documento oficial, abordando oito dimensões: gestão escolar; prática pedagógica; avaliação; acesso, permanência e sucesso na escola; ambiente educativo; formação dos profissionais do campus; relação escola-família; e integração escola-trabalho. 0 resultado do presente documento gerou ações que possibilitam subsidiar a prática na Educação Inclusiva.

Objetivou-se, entendendo a escola como esse espaço de influência que permite uma constante interação entre os sujeitos que ali se encontram, analisar o olhar de gestores e de funcionários de uma escola pública sobre o corpo de estudantes com deficiência.

\section{MÉTODOS}

\subsection{CARACTERIZAÇÃO DO ESTUDO}

Esta pesquisa é de natureza qualitativa, a qual se baseia em valores, crenças, representações, hábitos, atitudes e opiniões, objetivando entender o contexto no qual algum fenômeno ocorre, de maneira profunda e, quando necessária, de maneira subjetiva, não se preocupando, portanto, com mensurações e análises estatísticas (LANDIM et al., 2006). 


\subsection{PARTICIPANTES E LOCAL DA PESQUISA}

Participaram dessa pesquisa: um diretor, uma vice-diretora, uma coordenadora pedagógica, uma bibliotecária e uma auxiliar de serviços gerais. A pesquisa foi realizada em uma escola estadual situada em um município da Zona da Mata mineira, na qual, em 2019, estavam matriculados cinco alunos com deficiência, sendo que três possuíam professores de apoio. A escola não apresentava rampas de acesso para cadeirantes, piso tátil e ou banheiro acessível.

\subsection{INSTRUMENTO PARA PRODUÇÃO DE DADOS}

Utilizamos um roteiro de entrevista semiestruturado, contendo dez perguntas abertas inseridas em cinco eixos temáticos, a partir do qual o entrevistado teve a possibilidade de discorrer sobre o tema proposto em um ambiente semelhante ao de uma conversa informal. Entende-se, então, a entrevista semiestruturada como aquela que permite trazer diferentes informações do contexto e fenômeno investigado, possibilitando, assim, uma melhor compreensão e integralização dos dados durante 0 processo de análise (MORÉ, 2015).

$O$ roteiro de entrevista foi elaborado pela equipe de trabalho de acordo com os objetivos do estudo, não sendo testado antes de sua aplicação. 0 instrumento abordou as seguintes questões: I - Você acredita que a escola é acessível para os estudantes com deficiência física? Por quê? II - Qual sua função aqui na escola? O que você já fez/faz para incluir esse estudante? III - Como você vê o corpo desse estudante com deficiência? Ele pode fazer as mesmas coisas que os outros alunos? IV - Na aula de Educação Física, ele consegue fazer as mesmas coisas que os outros estudantes que não possuem qualquer tipo de deficiência? Será que ele consegue realizá-la? V - Você já presenciou alguma cena em que o estudante com deficiência sofreu preconceito ou discriminação no ambiente escolar? Caso afirmativo, você interveio de alguma forma?

\subsection{ASPECTOS ÉTICOS}

O estudo seguiu as normas estabelecidas pelo Conselho Nacional em Saúde sobre pesquisas, envolvendo seres humanos (Resolução 466/2012), tendo sido submetido e aprovado pelo Comitê de Ética em Pesquisa, com parecer número 3.915.111.

\subsection{PROCEDIMENTOS DE COLETA DE DADOS}

Iniciamos o contato com a direção da escola a fim de obter permissão para contatar os gestores e os funcionários, fornecer informações acerca do estudo, como os objetivos e o desenho metodológico, esclarecer sobre a garantia de anonimato na pesquisa e eventuais riscos e benefícios para os participantes. Prestados todos os esclarecimentos, solicitamos a assinatura do Termo de Consentimento Livre e Esclarecido (TCLE) a todos os que decidiram participar, viabilizando o início da coleta de dados. 
A escolha dos participantes ocorreu de forma aleatória, de modo que aqueles que estavam disponíveis no momento foram convidados a participar. Foi obtido o aceite por parte do diretor, da vice-diretora, da bibliotecária, do coordenador pedagógico e da auxiliar de serviços gerais. Os professores não foram contatados, pois haviam sido selecionados como amostra de outra pesquisa.

Após assinado o TCLE, os entrevistados foram conduzidos individualmente à sala da direção, onde a entrevista foi realizada pela pesquisadora. A entrevista foi gravada e, posteriormente, teve seu conteúdo transcrito pelas autoras, respeitando fielmente o que foi dito pelos entrevistados.

De forma a garantir o sigilo e anonimato dos participantes, os mesmos serão mencionados de acordo com o cargo/função que desempenham na escola (diretor, vice-diretora, coordenadora pedagógica, bibliotecária, auxiliar de serviços gerais).

\subsection{ANÁLISE E INTERPRETAÇ̃̃O DOS DADOS}

Os dados passaram pela análise de conteúdo nos princípios de Bardin (1977), definida como um conjunto de técnicas de análise de comunicações, sendo um leque de apetrechos. 0 processo segue as seguintes fases: pré-análise; exploração do material; tratamento dos dados, inferência e interpretação.

Desta forma, após a entrevista, as respostas foram analisadas e interpretadas, a fim de criar categorias de análise de acordo com o conteúdo abordado pelos entrevistados. Para fins de análise, foram criadas as seguintes categorias: I - Barreiras Arquitetônicas e os desafios da inclusão escolar; II- Humanização e superproteção da pessoa com deficiência; e III - Corpo e seu estigma de normalidade.

\section{RESULTADOS E DISCUSSÃO}

\subsection{BARREIRAS ARQUITETÔNICAS E OS DESAFIOS DA INCLUSÃO ESCOLAR}

Para o estudante com deficiência, um espaço escolar com todas as adaptações necessárias para torná-lo acessível é de extrema importância, pois permitirão que as atividades educacionais possam ser realizadas sem restrição de locomoção e sem limitação de suas tarefas escolares diárias. Participando ativa e integralmente das tarefas, seu corpo passa a ser visto pelos demais colegas e funcionários da escola como uma parte de si que é capaz de realizar tudo o que está ao seu alcance, reduzindo, assim, os estigmas e preconceitos acerca do corpo da pessoa com deficiência.

A inclusão dos alunos com deficiência dentro do espaço escolar foi discutida durante a entrevista. Foi notória a percepção de todos os entrevistados sobre a falta de infraestrutura acessível no ambiente escolar, reforçando a dificuldade para atender as demandas escolares necessárias à inclusão dos alunos com deficiência. Vejamos as falas a seguir:

[...] não tem rampa, a sala de aula não tem as portas para as cadeiras de rodas passar, não tem nada [...] (Vice-diretora); 
[...] nós temos poucas rampas aqui, os meninos deficientes têm que dar muitas voltas. Tem um banheiro para deficiente, mas raramente é usado, porque ele é afastado [...] (Bibliotecária);

[...] é difícil um cadeirante por exemplo, se locomover nela sozinho, precisa de ter um professor monitorando, controlando essa cadeira, ou um próprio colega[...] (Coordenadora pedagógica);

[...] por enquanto não é $100 \%$ acessível, tem uma verba para fazer rampa e piso tátil na entrada principal da escola, fazer uma rampa para saída, e piso tátil para as salas dois e três [...] (Diretor).

Segundo Wagner e colaboradores (2010), pessoas com deficiência enfrentam, comumente, limitações em sua vida diária. Essas limitações estão intimamente relacionadas à acessibilidade, ou seja, a condições que permitem ou impossibilitam o exercício da autonomia e a participação social do sujeito, podendo interferir ou prejudicar seu desenvolvimento ocupacional, cognitivo e psicológico e, consequentemente, contribuir com sua exclusão social.

Enquanto pensarmos que o espaço físico é destinado apenas para a população que se encaixa na sociedade como "padrão", ainda existirão pessoas que acreditam que acessibilidade e inclusão se resumem à uma pequena quantidade de vagas em estacionamentos destinada a indivíduos com deficiência física, ou rampas em vias públicas.

A escola deve proporcionar ao aluno com dificuldade de locomoção um ambiente adequado que ofereça condições para que ele possa transitar por todo o espaço, independentemente das limitações impostas pela sua deficiência, oportunizando-o mais autonomia e liberdade, não só no cotidiano escolar, mas também no convívio em sociedade.

Podemos perceber as dificuldades e limitações que a falta de acessibilidade ocasiona no dia a dia escola a partir da fala da bibliotecária:

[...] como prêmio no final do bimestre na biblioteca, eu levei os meninos, os leitores mais assíduos da biblioteca numa feira do livro que estava acontecendo em outra cidade. Um dos alunos que poderia ter ido era um cadeirante, só que o transporte que a gente conseguiu era da Prefeitura, então eu nem dei a notícia para ele da sua premiação. Primeiro eu procurei saber na prefeitura se o transporte seria acessível, porque se não fosse, eu não iria nem dar a notícia. E nós tentamos, mas o ônibus que ia levar não tinha elevador. Um aluno que gosta de ler, não pôde ir, porque não tinha o transporte para ele [...]

Pudemos perceber com o recorte anterior que o direito da pessoa com deficiência foi infringido duas vezes, sendo a primeira quando o mesmo nem se quer soube da sua premiação, e a segunda pela falta de acessibilidade.

Consideramos, aqui, que a acessibilidade está prevista na legislação a partir da Lei no 10.098, de 2000, a qual estabelece "normas gerais e critérios básicos para a promoção da acessibilidade das pessoas portadoras de deficiência ou com mobilidade reduzida" (Art. $1^{\circ}$ ), e do Estatuto da Pessoa com Deficiência - Lei no 13.146 de 2015, sendo o documento mais recente que regula o tema e que 
tem como objetivo assegurar e promover, em condições de igualdade, o exercício dos direitos e das liberdades fundamentais da pessoa com deficiência, visando sua inclusão social e cidadania, definindo a acessibilidade como a possibilidade e condição de alcance para utilização pela pessoa com deficiência ou mobilidade reduzida.

A Lei de Acessibilidade $n^{0} 10.098$ de 2000 estabelece normas gerais e critérios básicos para a promoção da acessibilidade das pessoas com deficiência ou com mobilidade reduzida, mediante a supressão de barreiras e de obstáculos nos espaços públicos, no mobiliário urbano, na construção e reforma de edifícios e nos meios de transporte e de comunicação. Desta forma, define acessibilidade como a possibilidade de utilização dos espaços, equipamentos, transportes, edifícios, informação, comunicação e serviços pelas pessoas com deficiência ou com mobilidade reduzida. Todavia, garantir a acessibilidade não necessariamente garante a inclusão social das pessoas com deficiência.

0 termo inclusão social pode ser entendido como a participação ativa nos grupos de convivência social, como por exemplo, a inclusão escolar. Rapoli e colaboradores (2010) afirmam que a inclusão vem para romper os paradigmas do conservadorismo nas escolas e garantir o direito à diversidade, pois, contesta os modelos tidos como ideais e a seleção de perfis específicos de estudantes para frequentarem as escolas, o que acaba por produzir diferenças, identidades, inserções e, ao mesmo tempo, exclusões.

Segundo Bonfim (2010), em meados da década de 1980 o Brasil deparou-se com um grande desafio político e social: promover a reintegração dos sujeitos, a redemocratização do sistema e o ressignificado das relações sociais por meio da cidadania. Foi nesse contexto que se iniciou uma análise dos movimentos sociais sob a ótica do direito social coletivo e da cidadania. A escola atual encontra-se nessa relação a partir do momento em que foi convidada a assumir a corresponsabilidade pelo processo de inclusão e efetivação da cidadania.

\subsection{HUMANIZAÇÃO E SUPERPROTEÇ̃̃O DA PESSOA COM DEFICIÊNCIA}

De acordo com Waldow e Borges (2011), as definições de humanização convergem para um sentido único, ou seja, humanização, humanidade e humanizar são o ato de tornar-se humano, dar condições humanas, agir com a bondade natural. E quando pensadas com relação à qualificação de uma conduta ou um cuidado, isso parece de uma forma redundante, pois não se pode admitir que um ser humano seja tratado de alguma outra maneira, senão aquela condizente com sua natureza.

No que tange às definições de superproteção, esta é conceituada como uma proteção excessiva, principalmente com um indivíduo que esteja em fase de desenvolvimento, implicando negativamente na sua autonomia. Isso pode ocorrer devido à um incentivo ou estímulo reduzido de seus limites e potencialidades, tornando-o incapaz de aprender a fazer suas escolhas com segurança (SILVA et al., 2019). Como exemplo de superproteção, temos o impedimento de vivenciar as situações de desafios que a vida impõe, limitando a autonomia da pessoa com deficiência e evitando que interações sociais saudáveis aconteçam (SILVA et al., 2019).

Para que essas interações e o agir com independência de fato aconteçam, é necessária uma infraestrutura adequada no ambiente escolar. Quando isso não é possível, observa-se a superproteção da pessoa com deficiência. 
Assim sendo, para assegurar a autossuficiência deste aluno, é garantida por lei ( $n^{0} 13.146$, de 6 de julho de 2015) a oferta de profissionais de apoio escolar com a função de auxiliar em atividades como alimentação, locomoção e higiene; ressaltando que este apoio não deve reduzir a autonomia e as possibilidades de aprendizado deste aluno, assim como, não ser interpretado com superproteção.

De forma expressiva, nota-se durante as entrevistas um excesso de humanização, levando a uma superproteção, com intuito de "amenizar/reparar" a falta de acessibilidade e de uma base pedagógica adequada. Observamos nas falas dos entrevistados que a exclusão social e presença da deficiência são condições cercadas somente de negatividade. Vejamos os recortes abaixo:

[...] pensamento em ajudar [os alunos com deficiência], porque são os que mais necessitam neste caso, todos necessitam, mas eles têm uma prioridade a gente faz uma questão de sempre acolhê-los com mais carinho dar atenção e assim vai. [...] incentivar a vir na aula, pedir os colegas para ter paciência com o aluno com deficiência ter humanidade, para um ajudar o outro [...] (Diretor).

[...] precisou de mim eu estou sempre pronto para ajudar. [...] ela ficava participando da Educação Física, mas não precisava de ajudar, né? Já tinha a professora de Educação Física, mas eu estava ali para ajudar [...] (Auxiliar de Serviços Gerais).

[...] olha, eu vejo os meninos da escola muito cuidadosos e muito carinhosos com esses meninos [com deficiência] (Bibliotecária).

Destacamos as expressões extraídas das falas anteriormente expostas: "Pensamento em ajudar"; "estou sempre pronto para ajudar"; "estava ali para ajudar"; "muito cuidadosos"; e "muito carinhosos”. Será que estes alunos de fato necessitam de assistência durante as atividades?

Para Mazzotta (2003), a política de inclusão reorienta as escolas para que prestem apoio aos programas de inclusão e registra como medida importante a garantia de vagas no ensino regular para todas as pessoas com deficiência. Desta forma, a aplicação da política de inclusão se concretiza ao garantir gestores e funcionários preparados para receber estes alunos com deficiência, no que tange às práticas educativas direcionadas ao aprendizado e demais demandas de locomoção, alimentação, higiene, dentre tantas outras presentes no cotidiano escolar, sem interferir na autonomia do aluno.

No que se refere ao papel dos gestores, este transita entre a função de integrador e de facilitador e promotor do desenvolvimento intelectual e profissional das pessoas com deficiência (SERRANO; BRUNSTEIN, 2008). O gestor tem o compromisso de incentivar práticas inclusivas e criar mecanismos para que a escola se torne mais humanitária e justa.

Desta forma, Dutra e Griboks (2005) ressaltam a importância de conhecer o papel do gestor escolar e as ações que estão sendo desenvolvidas, a partir de avaliações para identificar como o processo de inclusão acontece na escola, além de analisar as possibilidades de fazer deste espaço um ambiente de valorização das potencialidades dos alunos.

0 fato é que, no contato com alguém que desestabiliza o que internalizamos como normalidade, misturam-se fatores intelectuais, racionais, emocionais e afetivos, os quais, muitas vezes, geram ima- 
gens e informações impróprias e disposições psíquicas e afetivas em relação à determinada pessoa ou grupo (SOUZA, 2009). Por isso, é necessário nos policiarmos para que não utilizemos atitudes falsas que, na realidade, são excludentes, como o ato de apenas respeitar os alunos com deficiência, sem os valorizar como os demais estudantes.

\subsection{CORPO E SEU ESTIGMA DE NORMALIDADE}

Desde o início da história, os tipos de comportamento em relação às pessoas com deficiências eram de eliminação, destruição e menosprezo, os quais eram caracterizados pelos seus corpos e marcas (RECHINELI, 2008). Entendendo o corpo como um conjunto formado por cabeça, tronco e membros, o qual carrega a nossa história e identidade social, tudo aquilo que for contrário à essa definição será visto como diferente ou fora do padrão de normalidade (VOLP et al.,1995).

Ao que não responde aos padrões e aos quesitos estereotipados que a sociedade impõe, resta a rejeição e exclusão. A visão do corpo ocorre pelo olhar imposto pela cultura e pela forma com que este é caracterizado a partir da ótica de quem quer representá-la, criando-se assim, muitas vezes, um estigma que tende a agrupar seus semelhantes, na tentativa de amenizar seus defeitos aparentes.

A visão acerca do corpo dos estudantes com deficiência foi percebida atrelada ao discurso da normalidade, esquecendo que esse corpo não se dissocia da mente, como pode ser observado nos discursos a seguir:

[...] então eu vejo o caso dele muito complicado, até porque é uma doença degenerativa que aos poucos vai piorando, né? Ele não pode fazer as mesmas coisas que os outros [...] (Vice-diretora).

[...] o corpo dele é um corpo normal, porém sem o movimento das pernas no caso, dos alunos com deficiência. Então fisicamente não se vê nada diferente no corpo deles, o que se vê de diferente é que eles não têm o movimento das pernas. [...] (Bibliotecária).

[...] vejo com normalidade, acredito que ele tem condições de muitas das atividades que as vezes o aluno tido como normal não consegue fazer [...] (Coordenadora pedagógica).

[...] tem uns que não conseguem escrever, não tem jeito de pegar as coisas com a mão [...] (Auxiliar de serviços gerais).

[...] o corpo dele é atrofiado, ele tem dificuldade de movimento, o braço é mais fininho, as pernas são finas, mas não são compatíveis com um corpo normal [...] (Diretor).

De acordo com Meller e Tesche (2007), as pessoas com deficiência vivem duas situações: uma em que são consideradas como aquelas que não cumprem de maneira adequada e eficiente as exigências e as regras de convivência em sociedade; e outra em que não têm direito ao livre exercício de suas diferenças. 
No recorte anterior, a fala do Diretor evidenciou o seu olhar de "normalidade" frente ao corpo de uma pessoa com deficiência: "mas não são compatíveis com um corpo normal”. Seu entendimento é compartilhado pela maioria das pessoas, as quais buscam um corpo dentro dos padrões de uma normalidade construída pela sociedade, não enxergando a pessoa que está além do visível, e sim, somente sua deficiência.

Deste modo, "ser corpo deficiente não significa ser corpo ausente: ser corpo deficiente é ser corpo como outro qualquer [...] antes de ser corpo deficiente, ele é corpo e está presente no mundo" e, às vezes, temos deficiências na construção biológica, porém, no que tange à corporeidade, somos aptos (PORTO, 2005, p. 38-39 apud RECHINELI, 2008).

Segundo Amaral (1998), são três parâmetros utilizados para explicar o desvio da normalidade, sendo eles: critérios estatísticos, moda e média; caráter estrutural e funcional, forma e funcionamento; e cunho psicossocial "tipo ideal".

Como exemplo da média, temos a altura média do homem brasileiro, sendo considerados desviantes todos aqueles que desta se afastam. Em relação à moda, temos fatores constituídos historicamente a partir de uma maior frequência de distribuição de determinada característica, por exemplo. 0 critério estrutural e funcional está relacionado à "vocação" nas formas e funções na existência de determinadas características, e qualquer alteração nesta vocação caracteriza a pessoa que vive com essa condição como significativamente diferente. 0 terceiro parâmetro está voltado à comparação entre determinada pessoa ou grupo com o "tipo ideal”, construído e sedimentado pelo grupo dominante.

A partir disso entendemos, então, os parâmetros que "fundamentam" essas comparações dos corpos dos indivíduos com deficiência, tornando-as constantemente praticadas e percebidas com hegemonia nos discursos. A falta de um membro ou sua não funcionalidade são características, por exemplo, que possibilitam a realização de comparações, pelo fato de, muitas vezes, causarem estranheza. Isso acaba por se relacionar ao discurso da humanização e superproteção, uma vez que, devido ao reducionismo de uma visão que somente identifica a "falta" de alguma caraterística necessária para a constituição de um indivíduo "normal”, torna-se, equivocadamente, essencial que este seja tratado de forma privilegiada e com mais atenção.

\section{CONCLUSÕES}

A aceitação, o apoio e os incentivos estabelecidos pelos gestores e funcionários são fatores preponderantes na qualidade da inclusão das pessoas com deficiência no âmbito biopsicossocial, assim como, na forma com que esses sujeitos são percebidos pelos demais indivíduos com quem se relacionam. Desta forma, entender como essas relações são estabelecidas e como o corpo do indivíduo com deficiência é percebido, torna-se de fundamental importância para uma concretização dessas relações, de maneira com que o sujeito com deficiência tenha uma participação ativa.

Foi possível perceber que os corpos desses alunos são comparados ao padrão de normalidade, sendo entendidos e interpretados pela falta de alguma característica que os impedem de serem con- 
siderados “normais”. A superproteção e humanização também se fizeram presentes nas falas dos entrevistados, sendo identificadas como justificativas para suprir as dificuldades e obstáculos enfrentados pelos indivíduos que possuem alguma deficiência.

Conclui-se a necessidade de se compreender mais a fundo as relações estabelecidas entre os corpos dos indivíduos com deficiência, para que preconceitos e estigmas sejam desmistificados. Não podemos pensar sobre a pessoas com deficiência apenas do ponto de vista de um corpo fora dos padrões impostos historicamente pela sociedade.

Portanto, se faz necessária a utilização de recursos financeiros destinados à implementação de uma infraestrutura adequada que possibilite a inclusão efetiva das pessoas com deficiência neste ambiente, assim como, uma iniciativa por parte dos gestores escolares de se colocarem como principais agentes nesse processo de inclusão, disseminando-a para toda a comunidade escolar.

Diante da compreensão de corporeidade, surge uma nova visão de vida, a qual valoriza o potencial humano além do físico, abrangendo a interação social e psíquica, enxergando a essência que se faz presente em todos nós enquanto seres humanos.

\section{REFERÊNCIAS}

AMARAL, A. L. Sobre crocodilos e avestruzes: falando de diferenças físicas, preconceitos e superação. In: AQUINO, J. G. (org.). Diferenças e preconceitos na escola: alternativas teóricas e práticas. 8. ed. São Paulo: Summus, 1998.

BARDIN, L. Análise de conteúdo. Presses Universitaires de France. Tradução de Luís Antero Reto e Augusto Pinheiro. 70 ed., Lisboa: Edições 70, 1977.

BRASIL. Lei no 9.394, de 20 de dezembro de 1996. Lei de Diretrizes e Bases da Educação Nacional. Disponível em: http://www.planalto.gov.br/ccivil_03/leis/L9394.htm. Acesso em: 7 nov. 2019.

BRASIL. Lei $\mathbf{n}^{0}$ 10.098, de 19 de dezembro de 2000. Lei de Acessibilidade para pessoas com deficiência. Disponível em: http://www.planalto.gov.br/ccivil_03/leis/l10098.htm. Acesso em: 15 mar. 2020.

BRASIL. Lei n 13.146, de 6 de julho de 2015. Lei Brasileira de Inclusão da Pessoa com Deficiência. Disponível em: http://www.planalto.gov.br/ccivil_03/_Ato2015-2018/2015/Lei/ L13146.htm. Acesso em: 15 mar. 2020.

BRASIL. Base Nacional Comum Curricular. Educação é a Base. Ensino Médio. Brasília: Ministério da Educação, 2018. Disponível em: http://basenacionalcomum.mec.gov.br/images/BNCC_EI_ EF_110518_versaofinal_site.pdf. Acesso em: 15 mar. 2020. 
BONFIM, G. C. S. A prática da capoeira na educação física e sua contribuição para a aplicação da lei 10.639 no ambiente escolar: a capoeira como meio de inclusão social e da cidadania. Congresso Nordeste de Ciências do esporte, 3. 2010, Fortaleza: Anais [...], Fortaleza: Universidade Federal do Ceará, 2010. p. 1-12. Disponível em: http://congressos.cbce.org.br/index.php/conece/3conece/ paper/view/2379. Acesso em: 17 mar. 2020.

DUTRA, C. P.; GRIBOSKI, C. M. Gestão para a inclusão. Rev. Educ. Esp. n. 26, p. 1 - 5, 2005. Disponível em: https://periodicos.ufsm.br/educacaoespecial/article/view/4372/2566. Acesso em: 18 mar. 2020

DE SOUZA, R. A. et al. Construção colaborativa de um plano de ação para a educação inclusiva: como a experiência educacional finlandesa pode rechear esse processo? Rev. Ibero-Am. Est. Educ. v. 13, n. esp. 1, p. 576-585, 2018. Disponível em: https://periodicos.fclar.unesp.br/iberoamericana/ article/view/11457. Acesso em: 18 mar. 2020.

GUGEL, M. A. A pessoa com deficiência e sua relação com a história da humanidade. Ampid, 2007. Disponível em: http://www.ampid.org.br/v1/wp-content/uploads/2014/09/A-pessoa-comdefici\%C3\%AAncia-e-sua-rela\%C3\%A7\%C3\%A3o-com-a-hist\%C3\%B3ria-da-humanidade-1.pdf. Acesso em: 7 nov. 2019.

LANDIM, F. L. P. et al. Uma reflexão sobre as abordagens em pesquisa com ênfase na integração qualitativo-quantitativa. RBPS, v. 19, n. 1, p. 53-58, 2006. Disponível em: https://periodicos.unifor. br/RBPS/article/view/961. Acesso em: 7 nov. 2019.

LIMA. C. L. et al. Corpo, Corporeidade e deficiência. EDUCERE Congresso Nacional de Educação, 11, 2015, Curitiba: Anais [...], Cidade: Pontifícia Universidade Católica do Paraná/Curitiba, 2015. p. 19173-19184. Disponível em: https://educere.bruc.com.br/arquivo/pdf2015/20954_9999.pdf. Acesso em: 07 nov. 2019.

MARINHO, M. F. B. Educação inclusiva e formação de professores no município de Iranduba. 2007. 120 f. Dissertação (Mestrado) - Universidade Federal do Amazonas, Manaus, 2007.

MAZZOTTA. J. S. M. Identidade dos alunos com necessidades educacionais especiais no contexto da política educacional brasileira. Movimento Rev. Educ. n. 7, p. 11-18, 2003. Disponível em: http:// intervox.nce.ufrj.br/ elizabet/identidade.htm. Acesso em: 7 nov. 2019.

MELLER, V. A.; TESCHE, L. Vivências corporais de pessoas com deficiência. Visão Glob. v. 10, n. 1, p. 61-84, 2007. Disponível em: https://portalperiodicos.unoesc.edu.br/visaoglobal/article/ view/476. Acesso em: 7 nov. 2019. 
MORÉ, C.L.O.O. A "entrevista em profundidade" ou "semiestruturada", no contexto da saúde. Atas Investig. Qualit. Ciênc. Soc. v. 3, p. 126-131, 2015. Disponível em: https://proceedings.ciaiq.org/ index.php/ciaiq2015/article/view/158. Acesso em: 7 nov. 2019.

RAPOLI, E. A. et al. A educação especial na perspectiva da inclusão escolar: a escola comum inclusiva. Brasília: MEC, Secretaria de Educação Especial. Fortaleza: Universidade Federal do Ceará, 2010.

RECHINELI, A. et al. Corpos deficientes, eficientes e diferentes: uma visão a partir da educação física. Rev. Bras. Educ. Espec. v. 14, n. 2, p. 293-310, 2008. Disponível em: https://www.scielo.br/ pdf/rbee/v14n2/10.pdf. Acesso em: 7 nov. 2019.

SANT’ANA, I. M. Educação inclusiva: concepções de professores e diretores. Psicol. Est. v. 10, n. 2, p. 227234, 2005. Disponível em: https://www.scielo.br/pdf/pe/v10n2/v10n2a09.pdf. Acesso em: 7 nov. 2019.

SERRANO, C.; BRUNSTEIN, J. Competências dos gestores frente à inclusão da pessoa com deficiência: os desafios da diversidade na organização. Encontro da ANPAD, 32, 2008, Rio de Janeiro: Anais [...], Rio de Janeiro: Rio de Janeiro, 2008. Disponível em: http://www.anpad.org.br/ admin/pdf/EOR-B1677.pdf. Acesso em: 7 nov. 2019.

SILVA, E. P. A importância do gestor educacional na instituição escolar. Rev. Conteúdo, v. 1, n. 2, p. 67-83, 2009. Disponível em: https://www.academia.edu/24711029/A_IMPORT\%C3\%82NCIA_DO_ GESTOR_EDUCACIONAL_NA_INSTITUI\%C3\%87\%C3\%830_ESCOLAR. Acesso em: 7 nov. 2019.

SILVA P. F. et al. Os impactos emocionais e a superproteção familiar ao deficiente auditivo e surdo: barreiras na inclusão escolar. Simpósio de TCC e 14 Seminário de IC do Centro Universitário ICESP, 17, 2019, Águas Claras: Anais [...], Águas Claras: Centro Universitário ICESP/Águas Claras, 2008. p. 1777-1801. Disponível em: http://nippromove.hospedagemdesites.ws/anais_simposio/arquivos_up/ documentos/artigos/b6c1dca8ee4aae78fe70ebcfd36c2161.pdf. Acesso em: 7 nov. 2019.

SOUZA, H. S. H. Itinerários da inclusão escolar: múltiplos olhares e saberes e práticas. Ulbra: Porto Alegre, 2009.

UNESCO. Declaração de Salamanca sobre princípios, política e práticas na área das necessidades educativas especiais 1994. UNESCO, 1994. Disponível em: https://unesdoc.unesco.org/ark:/48223/ pf0000139394. Acesso em: 15 mar. 2020.

VOLP, C. M. et al. O conceito de corpo. Motriz, v. 1, n. 2, p. 107-110, 1995. Disponível em: http:// www.rc.unesp.br/ib/efisica/motriz/01n2/1_2_Catia.pdf. Acesso em: 7 nov. 2019. 
WAGNER, L. C. et al.; Acessibilidade de pessoas com deficiência: o olhar de uma comunidade da periferia de Porto Alegre. Ciênc. Mov. n. 23, p. 55-67, 2010. Disponível em: https://www.metodista. br/revistas/revistas-ipa/index.php/RS/article/view/94/58. Acesso em: 7 nov. 2019.

WALDOW, V. R.; BORGES R. F. Cuidar e humanizar: relações e significados. Acta Paul. Enferm. v. 24, n. 3, p. 414-418, 2011. Disponível em: https://www.scielo.br/scielo.php?pid=S0103$21002011000300017 \&$ script=sci_abstract\&tlng=pt. Acesso em: 7 nov. 2019. 
1 Graduada em Educação Física; Mestranda em Atividade Física e Saúde pela Universidade Federal de Viçosa. E-mail: betania.brasiliano@ufv.br

2 Especialista em Terapia Manual e postural pelo Centro Universitário de Maringá; Mestranda em Atividade Física e Saúde pela Universidade Federal de Viçosa; Graduada em Fisioterapia pela Univiçosa Facisa. E-mail: lais.b.alves@ufv.br

3 Doutora em Educação (PPGE/UFAL); Professora do Departamento de Educação Física e do Programa de Pós-Graduação em Educação da Universidade Federal de Viçosa. E-mail: soraya.dayanna@ufv.br

\section{(@) (1) (-)}

Este artigo é licenciado na modalidade acesso aberto sob a Atribuição-Compartilha Igual CC BY-SA

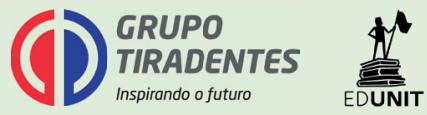

